Conclusions Parents wanted to participate in research with noninvasive sampling/salvage of waste. This provided valuable samples over extensive time periods. This could be used in other vulnerable groups. Bio-banking of such valuable samples may provide important opportunities for future research, avoid additional invasive sampling, and be time efficient.

\section{MITIGATION OF THE ALLERGIC ACTIVITY OF OVOMUCOID BY ELECTROLYSIS}

doi:10.1136/archdischild-2012-302724.0481

T Matsumoto. Child Development, Graduate School of Life Sciences, School of Medicine, Kumamoto University, Kumamoto, Japan

Ovomucoid (OMC) is the most prominent allergen causing egg allergy, and contains disulfide (S-S) bonds that may be responsible for its allergic action. As S-S bonds may be reduced during electrolysis on the cathode side, this study was undertaken to evaluate modulation of the allergic action of OMC after electrolysis. A current of $30 \mathrm{~mA} / \mathrm{cm}^{2}$ was applied. The allergic action was evaluated by means of skin prick tests (SPT) with egg-allergic patients, and the modification of OMC was examined by MALDI-ToF-MS after tryptic digestion. The total free $\mathrm{SH}$ groups in $1 \% \mathrm{OMC}$ solution were increased on the cathode sides after electrolysis for $30 \mathrm{~min}$ utes $(14.8 \mathrm{nmol} / \mathrm{ml})$ as against those of untreated OMC $(1.2 \mathrm{nmol} /$ $\mathrm{ml})$ and $\mathrm{OMC}$ on the anode side $(2.8 \mathrm{nmol} / \mathrm{ml})$. Significant mitigation of the wheal reactions by $22 \%$ were observed in the SPT with $\mathrm{OMC}$ on the cathode when compared with those for untreated OMC, however, the wheal reactions on the anode side did not differ from those for untreated OMC. The MALDI-ToF-MS results for untreated OMC or OMC on the anode side showed two peptide fragments suspecting potential S-S bonds (residues 63L-85S, $358 \mathrm{~A}-379 \mathrm{R})$ but, on the contrary, OMC on the cathode side did not give the fragments suspecting potential S-S bonds. The allergic action of OMC can be mitigated during electrolysis on the cathode side, being simultaneously formed intramolecular free $\mathrm{SH}$ groups. This study was supported by the Kieikai, Tokyo, and a Grant-inAid for Scientific Research from the Japan Society for the Promotion of Science.

\section{PROSPECTIVE MULTICENTER SURVEY OF COW'S MILK ALLERGY IN NICU NEONATES}

doi:10.1136/archdischild-2012-302724.0482

${ }^{1} \mathrm{~T}$ Miyazawa, ${ }^{1,2} \mathrm{~T}$ Imai, ${ }^{1} \mathrm{~K}$ Itabashi, ${ }^{3} \mathrm{M}$ Kimura, ${ }^{4} \mathrm{Y}$ Ohtsuka. 'Department of Pediatrics, Showa University School of Medicine, Tokyo; ${ }^{2}$ Clinical Research Center for Allergy and Rheumatology, National Hosipital Organization, Sagamihara National Hospital, Kanagawa; ${ }^{3}$ Department of Allergy and Clinical Immunology, Shizuoka Children's Hospital, Shizuoka; ${ }^{4}$ Department of Pediatrics, Juntendo University School of Medicine, Tokyo, Japan

Background and Aims Food hypersensitivity is a common cause of digestive symptoms in neonates. To confirm the diagnosis of neonatal cow's milk allergy (CMA), an oral food challenge (OFC) test should be conducted. However, many neonatologists in Japan avoid OFC because of excessive anxiety regarding induction of severe symptoms and continue to feed babies therapeutic formula without an accurate diagnosis. We conducted a prospective multicenter survey in which the standardized OFC was required in neonates with mild symptoms suggesting CMA.

Methods Neonates presenting with digestive symptoms suggesting CMA and who underwent OFC were enrolled between April 2010 and September 2011. Neonates with severe complications, inborn disorders or severe symptoms at the onset, such as anaphylaxis, mass gastrointestinal bleeding, or perforation, were excluded. This study was conducted as a multicenter survey of major NICUs in Japan.
Results OFC was performed in 52 neonates and positive inductions of symptoms were seen in 23 (44\%) of the challenged neonates. The majority had mild digestive symptoms which disappeared immediately after elimination of the causal milk. According to the results of OFC, the sensitivity, specificity, and positive predictive value of milk-specific IgE were $0 \%, 93 \%$, and $0 \%$, and those of the allergen-specific lymphocyte stimulation test were $61 \%, 76 \%$, and $67 \%$, respectively.

Conclusions Diagnostic OFCs for CMA were safely carried out in neonates. The discontinuation of certain foods as part of an elimination diet can lead to appropriate nutrition management. In NICUs, OFC should be carried out more aggressively with careful observation.

\section{REGIONAL REVIEW OF PAEDIATRIC RADIOALLERGOSORBENT TESTS ${ }^{\circledR}$ (RAST) OVER 5 YEARS IN IRELAND: AN EPIDEMIOLOGICAL STUDY IN A DEFINED BIRTH COHORT}

doi:10.1136/archdischild-2012-302724.0483

${ }^{1} \mathrm{~N}$ Feeney, ${ }^{2} \mathrm{~N}$ Barrett, 'RK Philip. 'Paediatrics; ${ }^{2}$ Biochemistry, University Hospital Limerick, Limerick, Ireland

Background and Aims RAST and related in-vitro tests assist in diagnosing childhood allergies.

Aims 1. To analyse paediatric RAST results and determine local prevalence of sensitivities, 2 . To develop guidelines towards recetly introduced ImmunoCAP ${ }^{\circledR}$ test panel selection incorporating local sensitivity prevalence in Ireland.

Methods RAST requests from 0-16 year population in Mid-West of Ireland were analysed between January 2004 to February 2009, excluding those not born in the Regional Maternity Hospital, to gain true birth cohort reflection of sensitivity patterns. Both total and allergen specific IgE levels were tabulated.

Results Total of 3033 successful sample requests for RAST (Immulite 2000) during the 62 month study period qualified for analysis Standardised classification system for allergen specific allergy levels showed mean total IgE of study population at $314.75 \mathrm{kU} / \mathrm{L}$ and median of $52 \mathrm{kU} / \mathrm{L}$ (expected elevated levels in a possible symptomatic patient sample). $76.8 \%$ of tests originated in hospitals and $23.2 \%$ from primary care. Most commonly tested allergen was house dust mite (1595) followed by Timothy grass (1155) and at $3^{\text {rd }}$ place food panel 5 comprising egg white, milk, cod fish, wheat, peanut \& soya bean. With standardised cut-off levels high and very high levels were noted frequently for egg $5.5 \%$, dust mite $19 \%$, timothy grass $14 \%$ followed by Horse, Cat and Dog. Our ImmunoCAP test guidelines incorporated information from RAST audit.

Conclusion Our paediatric RAST analysis provided regional allergen specific sensitivity pattern in Ireland thus assist ing clinicians in choosing appropriate allergens to be requested thus reducing cost and enhancing clinical relevance.

\section{CAN RESPIRATORY QUESTIONNAIRE COMPLETION BY PARENTS OBVIATE THE NEED FOR OUTPATIENT ASSESSMENT?}

doi:10.1136/archdischild-2012-302724.0484

LM Perrem, MB O’Neill. Mayo General Hospital, Castlebar, Ireland

Background and Aims Continuing care of asthmatic children is traditionally provided in outpatients settings. This study evaluated the effectiveness of both asthma and upper airway cough syndrome assessment by questionnaire and its acceptability to parents.

Methods The parents of children aged 4-13 years, attending an asthma clinic, were requested to complete the Asthma Control Test (ACT) and Respiratory Assessment Proforma (RAP). The RAP 